\title{
Barriers to translational research in Windsor Ontario: a survey of clinical care providers and health researchers
}

Justin B. Senecal' ${ }^{1}$, Karen Metcalfe ${ }^{2,4}$, Kaila Wilson $^{2}$, Indryas Woldie ${ }^{1,2,3,4^{*}}$ and Lisa A. Porter $2,4^{*}$ (D)

\begin{abstract}
Background: Translational research is an ideology focussed on streamlining the transition of novel research into clinical practice to ultimately benefit populations. Central to this approach is overcoming barriers to research involvement and interdisciplinary collaboration. Identifying barriers has been the subject of several studies focused on communities with large academic hospitals. The Windsor-Essex region is currently built around community hospitals which have less of an emphasis on research, employ fewer physicians holding academic appointments and generally do not provide incentivised time for research and training. In this study, we surveyed clinicians and researchers working in Windsor-Essex to gain insight into barriers to translational research important to those working in smaller sized, community-based research networks.
\end{abstract}

Methods: Using an anonymous close-ended Qualtrics survey distributed via email, we surveyed faculty members from The University of Windsor and clinical care providers from Windsor-Essex $(n=68)$. This included 24 physicians, 14 allied health professionals, and 30 non-clinician researchers.

Results: Managing competing interests, lack of time, funding, infrastructure, and networks were identified by greater than $75 \%$ of participants as barriers to research involvement. $62 \%$ of physicians identified the lack of permanent post-graduate medical trainees as a barrier. Clinicians were consistently less experienced in research skills compared to others; particularly in publishing results and applying for funding $(p<0.001)$. Schedule incompatibility, funding issues and identifying interested collaborators with overlapping interests were identified as barriers to interdisciplinary collaboration by $80 \%$ of participants. Moreover, $46 \%$ of those surveyed were unhappy with their research involvement and these individuals were 13\% more likely to perceive research as important for their career progression $(p=0.244)$.

Conclusions: This study identifies several important barriers to translational research in Windsor-Essex and suggests that many motivated researchers are unhappy with their current involvement. These results will inform decision making in the research community of Windsor-Essex and provides insight for communities of similar size and research capacity. Ultimately, enabling the translation of clinical research in all communities is required to ensure equitable access to cutting edge care.

Keywords: Barriers, Translational research, Interdisciplinary collaboration, Research participation

*Correspondence: Indryas.Woldie@wrh.on.ca; Iporter@uwindsor.ca

${ }^{1}$ Schulich School of Medicine and Dentistry, London, ON, Canada

${ }^{2}$ WE-SPARK Health Institute, Windsor, ON, Canada

Full list of author information is available at the end of the article

\section{Background}

Windsor, ON is the third-most populous city in Southwestern Ontario. It is home to the 7th largest community teaching hospital, Windsor Regional Hospital (WRH), a post-acute community hospital Hôtel-Dieu Grace Healthcare, and the 14th largest university by 
enrollment, The University of Windsor (UoW), in the province $[1,2]$. The city also hosts the Schulich School of Medicine and Dentistry's lone distributed medical campus and permanent postgraduate medical trainees in family medicine and psychiatry. The health research community continues to grow, with the new translational research institute WE-SPARK Health Institute recently launching in the spring of 2020. Still, compared to the largest research networks in the country, the health research capacity is limited.

Barriers to participation in health research and interdisciplinary collaboration have been the subject of many studies, often in the context of identifying barriers to translational research (TR) [3]. TR is often described as "bench to bedside" and is focussed on streamlining novel research findings into widespread clinical changes $[4,5]$. Central to this ideology is a multidisciplinary approach, requiring the input of both clinical care providers and graduate trained researchers. These two groups often experience different barriers to their research goals; likely due to their different educational backgrounds and professional responsibilities [6].

The generalizability of previous studies are questionable for the following reasons: past studies often take place in large, academic centers $[3,7,8]$, they often only include those heavily involved in research $[3,7$, $9,10]$, and the resulting barriers are broad and difficult to interpret [3]. Unlike academic centres, community centres like WRH have less research funding, employ many physicians that lack academic appointments and do not generally provide incentivised protected time for research or training; though a precise definition is lacking [11]. While most clinical and translational research conducted in Canada takes place in these large academic centres, the benefits of conducting research in community hospitals like WRH is substantial for both researchers and patients [11]. Given the limitations of previous work, we set out to examine which TR barriers are important to a smaller research community and community-based hospitals. We surveyed clinicians and health researchers from Windsor-Essex and specifically examined participants' confidence in research tasks, opinions on TR, barriers to health research participation and interdisciplinary collaboration. We identified several major barriers to research and collaboration in our community and found that those struggling with their research involvement perceived barriers differently. Our findings will inform decision-making in the Windsor-Essex research community and contribute to the understanding of TR barriers in smaller centres.

\section{Methods}

\section{Survey design}

We designed an Internet-based survey using Qualtrics, an established survey provider, to examine research experience, opinions on TR, barriers to participation in health research and barriers to interdisciplinary collaboration in Windsor-Essex. The survey was anonymous and close-ended. We first asked participants about their professional backgrounds; with a focus on identifying those with clinical care responsibilities. We also asked participants about their satisfaction with research involvement, faculty appointments, time spent on research and research area. We then divided participants into the following groups: clinical care provider vs non-clinicians, and happy vs unhappy with current research involvement. Much of the questionnaire was adapted from previous studies that explored these barriers in other locations $[7-9,12]$. Others were designed by the research team based upon their experiences working in WindsorEssex. We choose not to collect certain demographics, such as age, gender, and specific research area, as these are beyond the scope of the study and could potentially allow for individual participants to be discerned in our relatively small research community.

We provided participants with a list of barriers to research participation and interdisciplinary collaboration identified in previous studies $[8,12]$ and asked them to rate the impact of each barrier with the following Likert Scale: Not a barrier (0), Moderate Barrier (1), Major Barrier (2). Clinical care providers were asked about barriers to collaborating with non-clinical care providers and vice versa. Participants that have experienced such collaboration in the past were also provided a list of benefits and selected which benefits they experienced. We also asked participants to rank their confidence in a variety of research tasks (adapted from [12]) using the following Likert Scale: No (1), Little (2), Some (3), Moderate (4) and Very (5) Experienced.

To assess participants opinions on research productivity and TR, we provided participants with a list of research metrics and achievements (adapted from [7, 9]) and asked them to choose no more than 4 that were relevant to their careers. We then provided them with a series of statements on TR and asked them to rank their agreement using this Likert Scale: Strongly disagree (1), Disagree (2), Neither agree or disagree (3), Agree (4), Strongly Agree (5).

\section{Study recruitment}

Between July 2nd 2020 and Nov. 30th 2020, participants were recruited via email and community newsletter. Standardized emails including the survey link were sent 
to faculty members from the Faculty of Arts and Humanities, Kinesiology, Engineering, Science and Nursing at the UoW by their respective deans. Clinical care providers working at Windsor Regional Hospital were distributed emails via the Research Office with permission from the Chief of Staff. The link was also included in newsletters at WRH, UoW and WE-SPARK.

Participants were included in the study if they satisfied the following criteria: (1) the participant worked in Windsor-Essex, (2) was a clinical care provider or had research interests that "May have implications for healthcare policy, clinical care, treatment development or clinical education", and (3) completed greater than $2 / 3$ of the survey.

\section{Statistical analysis}

Data from the questionnaire was imported into Excel 2020 (Microsoft Corporation, USA). Descriptive statistics (Likert values, proportions, frequency counts) were used to capture demographic data for the study population; as well as perceptions on barrier to research and interdisciplinary collaboration, confidence in research skills and opinions on TR. Statistical comparisons between groups (clinical care providers vs non-clinicians; unhappy vs happy with research involvement) was performed with an independent, unpaired t-test. Results were considered significant if $\mathrm{p}<0.05$.

\section{Ethics statement}

This study received clearance from the Research Ethics Board of the UoW and WRH (REB\# 37036). Informed consent was obtained from participants before they began the survey.

\section{Results}

Study participants and response rate

To assess which barriers to health research participation and interdisciplinary collaboration were important to those working in Windsor-Essex, we recruited clinicians from the area and faculty members from UoW to participate in our survey. 88 respondents completed some of the survey. 20 did not meet the inclusion criteria, leaving 68 participants that were included in the study. 10 of the included participants submitted partial surveys that were greater than $66 \%$ complete, the rest were completed in entirety. Amongst faculty members from the targeted faculties at the UoW, we received 40 responses from an estimated 447 members [Response Rate $(R R)=9 \%$ ]. 24 physicians from WRH responded out of an estimated 485 physicians $(R R=5 \%) .14$ allied health professionals also contributed, but we are unable to estimate a total number of these professionals that were recruited. A total RR is likely higher than each individual RR combined due to physicians that are also UoW faculty.

As seen in Table 1, 38 (56\%) of the participants were clinical care providers and $30(44 \%)$ were not. Of the clinical care providers, 24 (63\%) were physicians and 14 (37\%) were allied health professionals, including nurses, social workers, and physiotherapists. $87 \%$ of clinical care providers spent less than $20 \%$ of their time on research compared to only $10 \%$ of non-clinicians. $90 \%$ of participants that were non-clinicians had a graduate degree, compared to only $43 \%$ of clinicians. Participants carried out a variety of research tasks and had a variety of research interests, but clinical research was the most common, particularly amongst clinical care providers (Additional file 1: Figure S1).

Table 1 Characteristics of survey respondents $n=68$

\begin{tabular}{|c|c|c|c|c|c|}
\hline & All & Clinical care provider & Non-clinician & $\begin{array}{l}\text { Happy with } \\
\text { research } \\
\text { involvement }\end{array}$ & $\begin{array}{l}\text { Unhappy } \\
\text { with research } \\
\text { involvement }\end{array}$ \\
\hline Total & $68(100 \%)$ & $\begin{array}{l}38(56 \%) \\
\text { Physician: } 24 \text { (35\%) } \\
\text { AHP: } 14 \text { (20\%) }\end{array}$ & $30(44 \%)$ & $31(46 \%)$ & $31(46 \%)$ \\
\hline$<20 \%$ time spent on research & $36(53 \%)$ & $33(87 \%)$ & $3(10 \%)$ & $14(45 \%)$ & $17(54 \%)$ \\
\hline $\mathrm{PhD}$ & $33(48 \%)$ & $6(16 \%)$ & $27(90 \%)$ & $18(58 \%)$ & $13(42 \%)$ \\
\hline No graduate degree & $25(37 \%)$ & $22(57 \%)$ & $3(10 \%)$ & $6(19 \%)$ & $11(35 \%)$ \\
\hline MD & $24(34 \%)$ & $24(63 \%)$ & $0(0 \%)$ & $10(32 \%)$ & $9(29 \%)$ \\
\hline University of Windsor & $35(52 \%)$ & $11(29 \%)$ & $24(80 \%)$ & $17(54 \%)$ & $15(48 \%)$ \\
\hline Schulich School of Medicine and Dentistry & $18(26 \%)$ & $17(45 \%)$ & $1(3 \%)$ & $6(19 \%)$ & $8(26 \%)$ \\
\hline No Faculty Affiliation & $16(23 \%)$ & $11(29 \%)$ & $5(17 \%)$ & $8(26 \%)$ & $7(22 \%)$ \\
\hline St. Clair College & $2(3 \%)$ & $2(3 \%)$ & $0(0 \%)$ & $1(3 \%)$ & $1(3 \%)$ \\
\hline Unhappy With Research Involvement & $31(46 \%)$ & $20(53 \%)$ & $11(37 \%)$ & N/A & N/A \\
\hline
\end{tabular}




\section{Research satisfaction and career development}

To assess whether participants were satisfied we asked whether they agreed with the statement "I am happy with my current research involvement." 46\% of participants were unhappy with their current research involvement, including $53 \%$ of clinical care providers and $37 \%$ of nonclinical care providers (Table 1). We then asked participants whether they felt research was important for their career progression (Additional file 1: Figure S2). Interestingly, those that were unhappy with their research involvement were more likely to state that research was important for their career progression when compared to those that were happy with their current research ( $83 \%$ vs $70 \%, \mathrm{p}=0.244$; Additional file 1: Figure S2).

\section{Barriers to research participation}

To determine which barriers to research participation were important to those working in Windsor-Essex, respondents were asked to rank the impact of various barriers using a Likert Scale (Fig. 1A). Managing competing activities, lack of time, funding and infrastructure were the most impactful barriers in the opinion of the participants (Fig. 1A); with more than $85 \%$ of participants identifying each as a moderate or major barrier. Clinical care providers and non-clinicians perceived the impact of each barrier as relatively equal, with the largest discrepancy being that non-clinicians perceived recruiting and training research staff as significantly more impactful than clinicians $(p=0.0135$; Fig. 1A). Those that were unhappy with their research involvement identified lack of institutional support and mentorship as significantly more impactful than those that were happy with their research involvement $(\mathrm{p}<0.05$, Fig. 1A).

We also asked participants how experienced they were in a variety of common research tasks using a Likert Scale (Fig. 1B). Clinicians perceived themselves as significantly less experienced than non-clinicians in all research tasks we included $(p<0.01$, Fig. 1B). The largest differences were in publishing results, applying for research funding, and writing research protocols (Fig. 1B). There was a similar trend when participants were divided by their satisfaction with research involvement, with those that were happy generally feeling more experienced than those who were unhappy. However, the differences were not as large (Fig. 1B). 62\% of physicians surveyed also felt that the lack permanent postgraduate trainees in the area was a barrier to their research goals (Fig. 1C).

\section{Barriers to interdisciplinary collaboration}

We asked clinicians to rank the impact of various barriers to collaboration with non-clinicians and vice versa using a Likert scale. Most barriers were equally impactful to clinical care providers and non-clinicians, with greater than $80 \%$ of participants identifying schedule incompatibility, lack of funding, identifying interested collaborators and lack of shared infrastructure as barriers (Fig. 2A). Clinicians felt that lack of institutional support was more impactful than non-clinicians, and it was the most impactful barrier identified by this group $(p=0.0115$, Fig. 2A).

$38 \%$ of clinical care providers in our study have collaborated with non-clinicians on research tasks and $40 \%$ of non-clinicians have collaborated with clinicians. Interestingly, all barriers to interdisciplinary were ranked as more impactful by those that had experienced interdisciplinary collaboration (NS; Data not shown). Participants who have experienced interdisciplinary collaboration were asked to identify what benefits they experienced (Fig. 2B). Access to expert opinions/new knowledge, different skills and additional funding were the most frequently cited benefits, while increased publications was the least frequently identified benefit (Fig. 2B). Non-clinicians were significantly more likely to cite improved access to patient data or tissues as a benefit when compared with clinicians ( $31 \%$ vs $12 \% ; \mathrm{p}=0.049$ ). This was the only significant difference between the two groups.

\section{Opinions on research productivity and TR}

To assess the participants' opinions on research productivity, we asked each to identify which metrics and achievements were important to them. Traditional achievements, including conference presentations and publications, were identified by more than $50 \%$ of our participants as important for career progression (Fig. 3A). Clinicians were more likely to identify first author publications as more important than other publications (Fig. 3A). Publications that were neither first nor last author were identified as important by non-clinicians more so than clinicians ( $70 \%$ vs $40 \%$; $\mathrm{p}=0.0189$ ). Nonclinicians were significantly more likely to use number of citations and awards/grants to measure the impact of their research $(\mathrm{p}<0.01$; Fig. 3B).

We next asked participants how confident they were in their understanding of TR. $46 \%$ of participants were either confident or very confident in their understanding of TR (Fig. 4A). Clinicians were more likely to lack confidence than non-clinicians ( $43 \%$ vs $11 \%$; Fig. $4 \mathrm{~B}$ ). Using a Likert scale to rate agreement with statements about TR, we found that fewer clinical care providers felt that their research would be considered translational or had the training to participate in translational projects as compared to non clinicians $(\mathrm{p}<0.001$; Fig. $4 \mathrm{~B})$. Most of the participants were unsure whether their research required translation, however, clinicians were less likely to feel that their research goals required translation $(\mathrm{p}=0.0029$; Fig. 4B). 


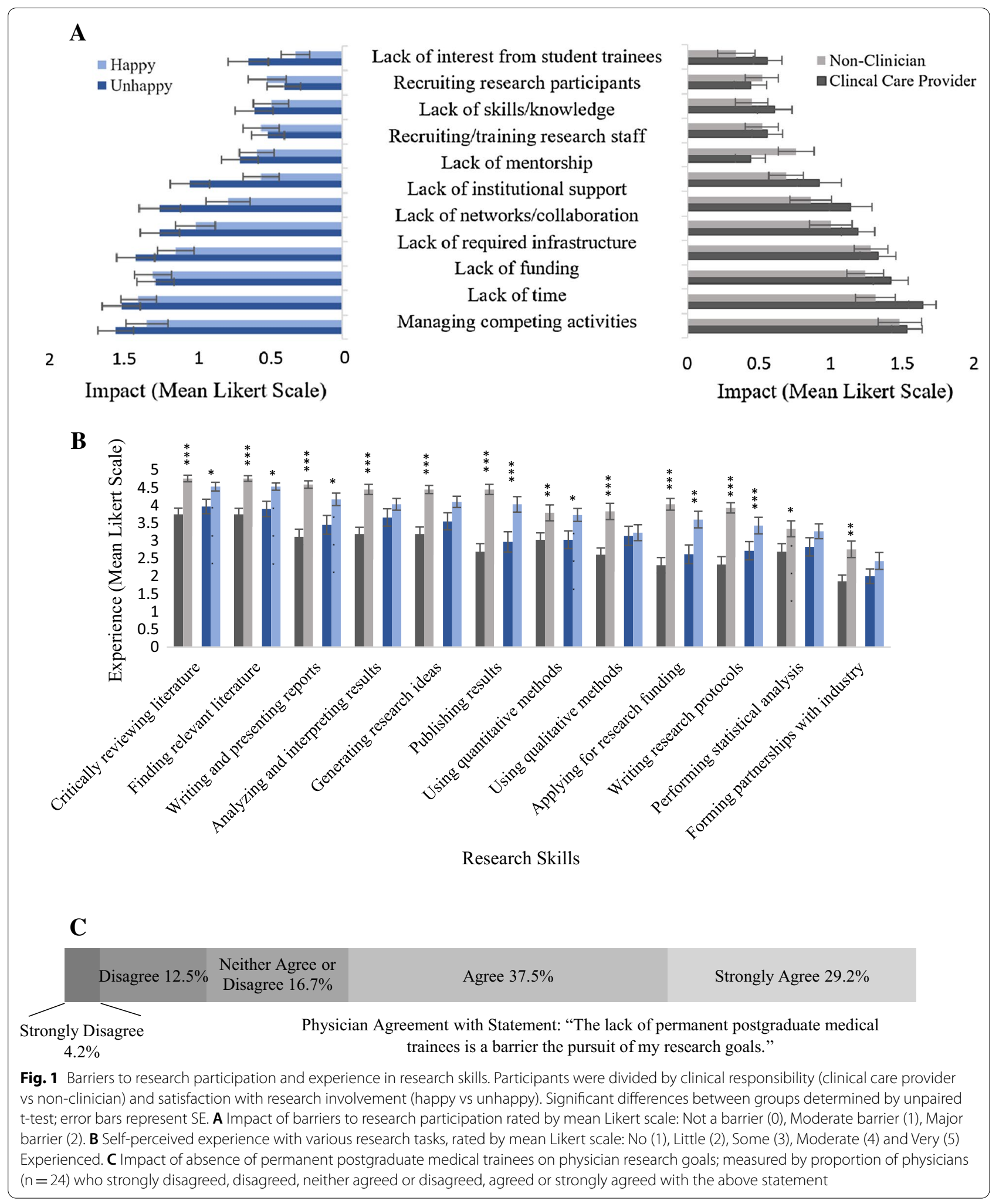




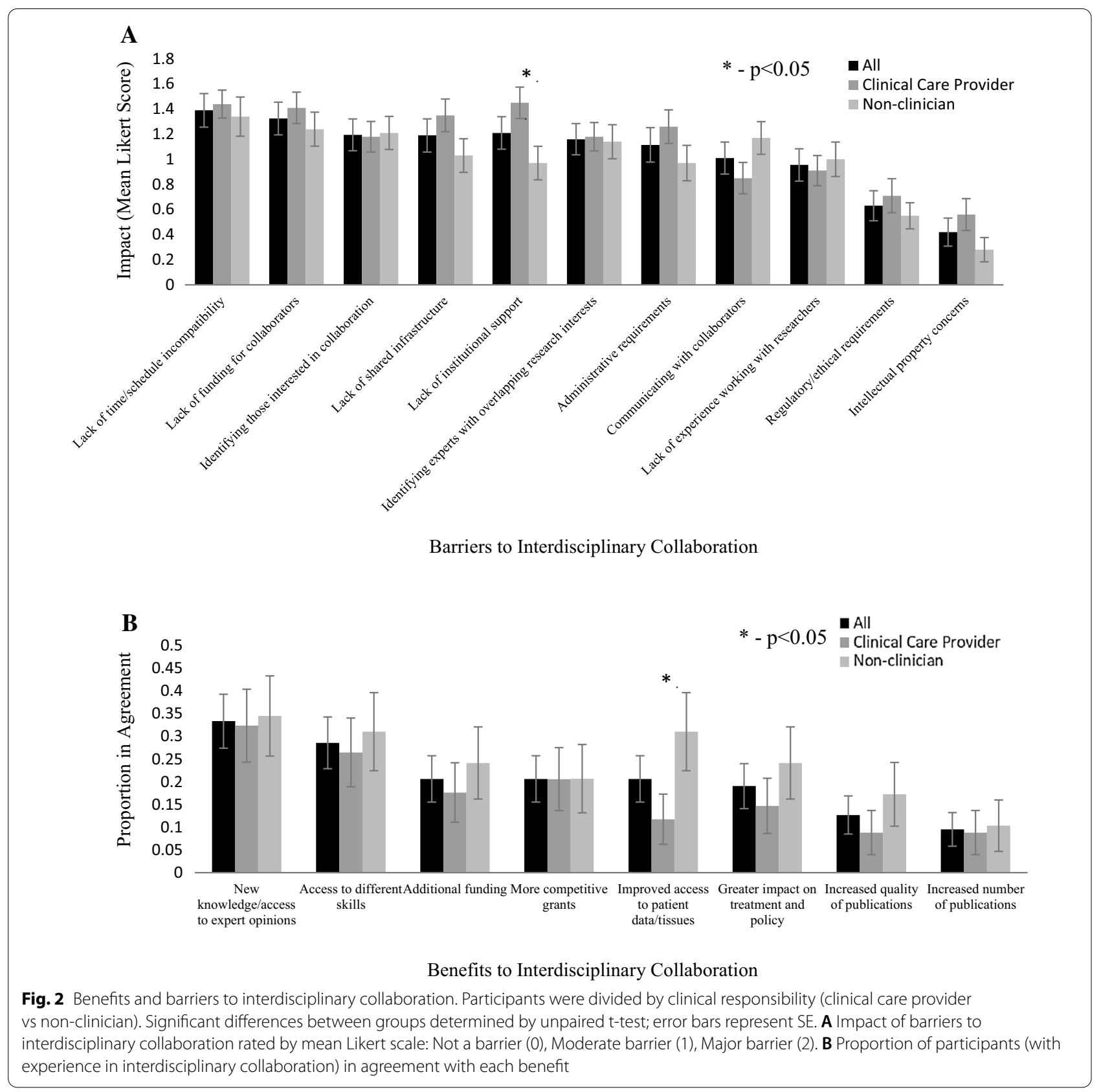

\section{Discussion}

In this study, we surveyed health researchers from a mid-sized comprehensive University that lacks a full medical school campus to assess the barriers to research participation and interdisciplinary collaboration. To our knowledge, this is the first such study in a smaller, Canadian research community that contains only community hospitals. Key findings are summarized in Fig. 5. We also sorted our findings into 3 of the 5 thematic barriers identified in the narrative synthesis by Fudge et al. [3]; including "Research Process",
"Interdisciplinary Collaboration" and "Concepts of Translational Research" (Fig. 5).

We included participants with various research interests from clinical and non-clinical backgrounds across a range of disciplines; reflecting the growing group of professionals that contribute to health research [4] (Additional file 1: Figure S1, Table 1). $46 \%$ of study participants felt unhappy with their current research involvement and $83 \%$ of these individuals felt that research was important for their career progression (Additional file 1: Figure S2)(Table 1). This suggests that there is a group of 


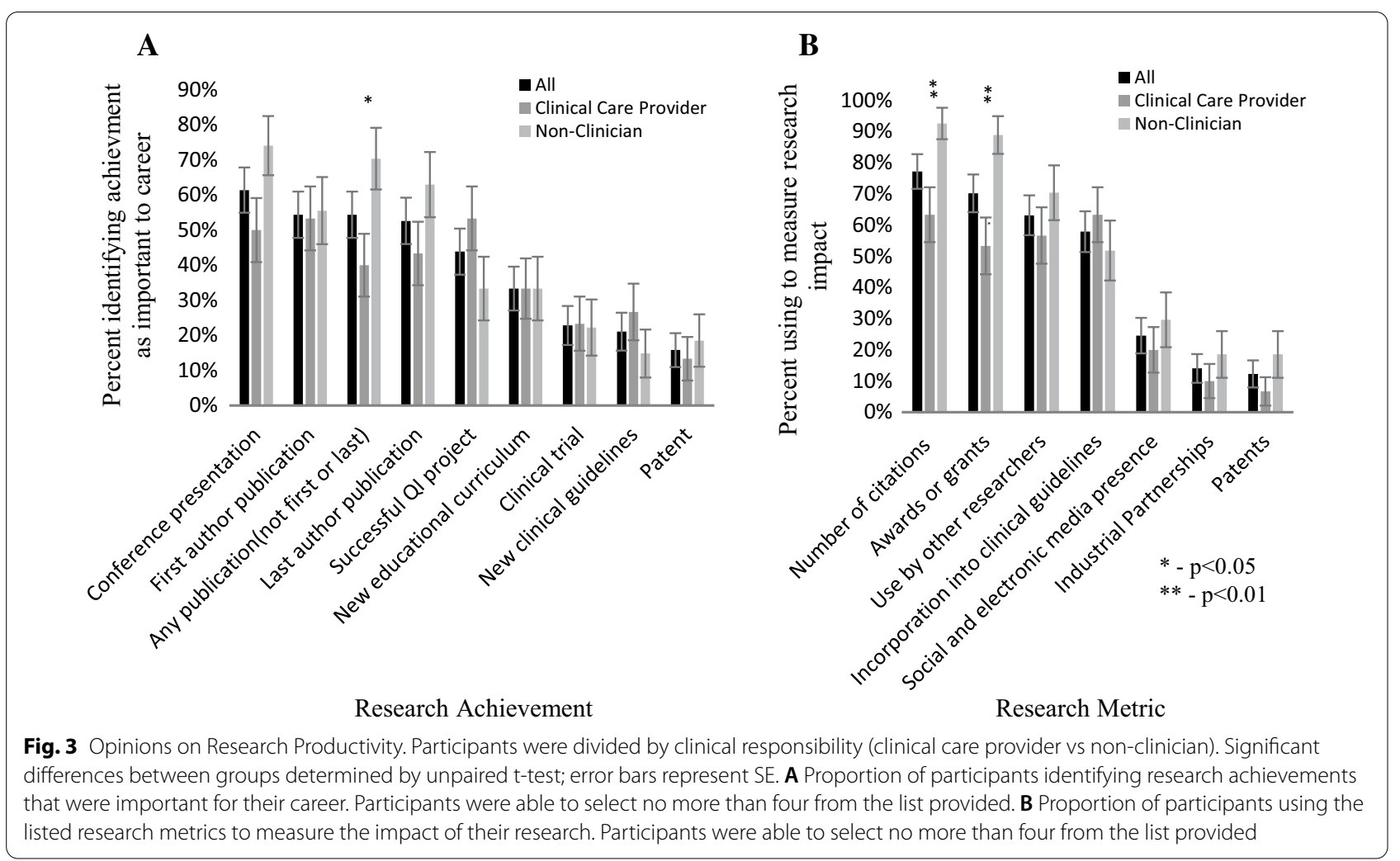

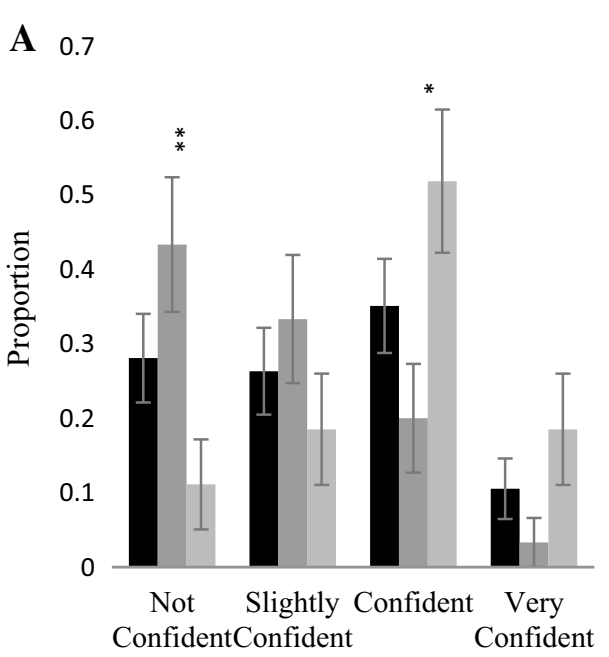

Confidence in Understanding of
Translational Research

\section{B}

I have the training to contribute to translational research projects

My research goals do not require translation

My research is translational

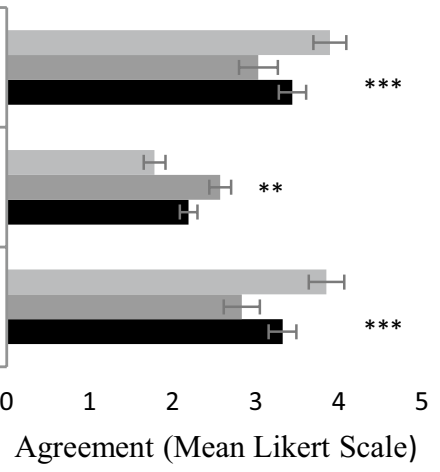

Non-Clinician
Clinical Care Provider
All$$
*-\mathrm{p}<0.05
$$$$
* *-\mathrm{p}<0.01
$$$$
* * *-\mathrm{p}<0.001
$$

Fig. 4 Opinions on Translational Research. Participants were divided by clinical responsibility (clinical care provider vs non-clinician). Significant differences between groups determined by unpaired t-test; error bars represent SE. A Participant confidence in understanding of translational research. B Participants were asked whether they agree with the listed the statements. Agreement of each group was measured via mean Likert scale: Strongly disagree (1), Disagree (2), Neither agree or disagree (3), Agree (4), Strongly Agree (5) 


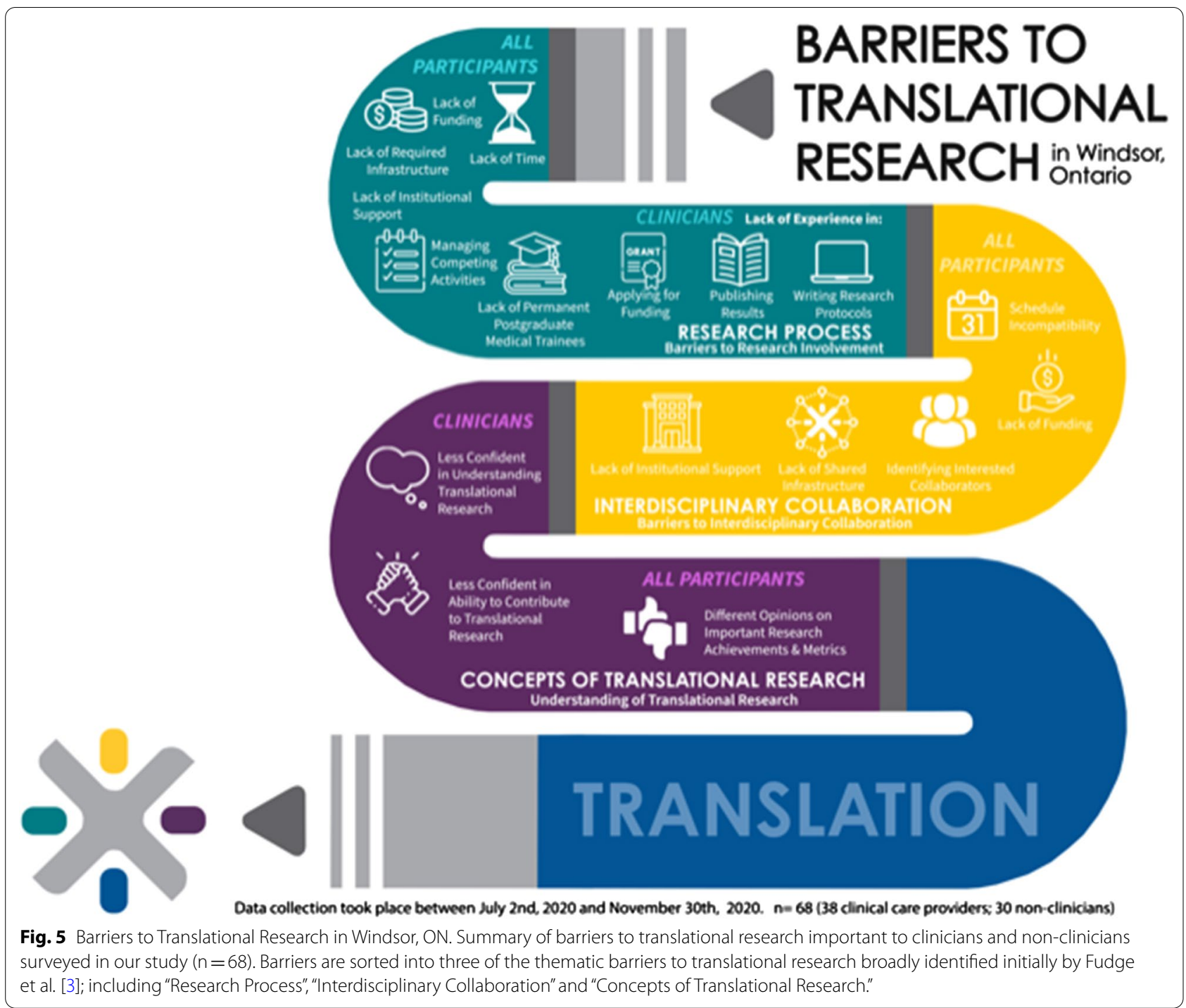

motivated but dissatisfied researchers in this community. This group felt that lack of mentorship and institutional support were significantly more impactful than those that were happy with their current research involvement (Fig. 1A). The data agrees with a survey of Canadian respiratory workers, which suggested that lack of mentorship was a more important barrier for those not involved in research when compared to those actively engaged in research [12]. Clinicians and non-clinicians ranked barriers to research participation relatively equally (Fig. 1A), with more than $85 \%$ of participants selecting managing competing activities, lack of time, funding, and infrastructure as a barrier. These barriers have been frequently cited as important to researchers in studies from other geographic areas $[8,10,12,13]$.
Study participants with clinical responsibilities were significantly less confident than non-clinicians in research skills, with the largest disparity being in applying for research funding and publishing results (Fig. 1B). Previous studies have also suggested that this lack of confidence could be a barrier to participating in interdisciplinary collaboration, particularly with colleagues who are more research focussed $[9,12]$. Clinicians and non-clinicians generally agreed on the benefits and barriers to interdisciplinary collaboration (Fig. 2A); with $80 \%$ identifying schedule incompatibility, lack of funding, identifying interested collaborators and lack of shared infrastructure as a moderate or major barrier. Both groups also tended to find traditional research metrics, such as publications, presentations, and citations, as the 
most significant metric of research productivity (Fig. 3). This is in contrast to previous work which suggested that clinical researchers found incorporation into clinical guidelines as more important than publications [14]. Furthermore, non-clinicians were more confident in their understanding of TR and largely felt that they had the necessary training to contribute to TR. Non-clinicians also felt that their research was either already translational or requires translation (Fig. 4).

A strength of this study is our broad sample that is inclusive of participants with different research commitments, backgrounds, and clinical responsibilities. However, this sampling strategy did lead to a relatively low response rate and potential response bias. Physicians in particular are known to be difficult to survey, with previous studies reporting response rates as low as $2.7-11.4 \%$ $[15,16]$. In addition, our strategy likely selects for participants with an interest in translational research, which may be a smaller proportion of individuals in a community-based research environment. By dividing participants based on their satisfaction with their research involvement, we assured that our findings weren't biased by those with particularly favourable or unfavourable views of the research community.

While the close-ended nature of the survey makes drawing conclusions difficult, our data suggests that mentorship and assistance with obtaining grants would benefit researchers in Windsor-Essex. Plans to develop a database of interested researchers to aid with identification of interested collaborators are already underway in our community. Other barriers, such as managing competing activities and schedule incompatibility, are more difficult to address as they are ingrained in the culture of various careers. Future studies should allow for narrative responses to better identify problems and potential solutions.

\section{Conclusion}

In summary, we found that while clinicians and non-clinicians from Windsor-Essex perceive similar barriers to research participation and interdisciplinary collaboration, they differ in terms of their confidence in research skills and their opinions on TR. Lack of mentorship, and institutional support were more important barriers to those that were dissatisfied with their current research involvement; but future study is needed to better define these barriers. These findings will inform decision making in Windsor-Essex and similarly sized research communities that are often neglected in these studies.

\section{Abbreviations}

AHP: Allied Health Professional; RR: Response rate; TR: Translational research; UoW: University of Windsor; WRH: Windsor Regional Hospital.

\section{Supplementary Information}

The online version contains supplementary material available at https://doi. org/10.1186/s12967-021-03097-6.

Additional file 1. Supplemental Figures and the Distributed

Questionnaire

\section{Acknowledgements}

We acknowledge the support of WE-SPARK Health Institute in securing the partnerships that made this work possible. We acknowledge all the participants in this study, given that time is a major constraint for research their time was most appreciated on this work.

\section{Authors' contributions}

JS was responsible for data/statistical analysis, survey design, and was a major contributor in writing the manuscript. LP was principal investigator on the project and served as faculty supervisor and covered manuscript costs. LP, KM and IW contributed to the study design, data analysis and editing of the manuscript; they also facilitated survey distribution. KW developed our graphical summary displayed in Fig. 5. All authors read and approved the final manuscript.

\section{Funding}

This project was supported by Schulich-UWindsor Opportunities for Research Excellence Program (SWORP) sponsored by the University of Windsor and the Schulich School of Medicine and Dentistry, Western University (Justin Senecal). Publication costs were covered by a Canadian Institutes of Health Research (CIHR) grant \#145983 (Lisa A. Porter).

\section{Availability of data and materials}

All data generated or analysed during this study are included in this published article [and its additional information files].

\section{Declarations}

\section{Ethics approval and consent to participate}

This study received clearance from the Research Ethics Board of the UoW and WRH (REB \# 37036). Informed consent was obtained from participants before they began the survey.

\section{Consent for publication}

No identifying data was collected in the study, but participants consented to the use of the data in publication before they were provided access to the survey.

\section{Competing interests}

The authors declare that they have no competing interests.

\section{Author details}

${ }^{1}$ Schulich School of Medicine and Dentistry, London, ON, Canada. ${ }^{2}$ WE-SPARK Health Institute, Windsor, ON, Canada. ${ }^{3}$ Cancer Program, Windsor Regional Hospital, Windsor, ON, Canada. ${ }^{4}$ Department of Biomedical Sciences, University of Windsor, Windsor, ON, Canada.

Received: 1 July 2021 Accepted: 27 September 2021

Published online: 27 November 2021

\section{References}

1. Universities Canada. Enrollment by University. 2020. https://www.univc an.ca/universities/facts-and-stats/enrolment-by-university/. Accessed 9 Apr 2020

2. WRH. About WRH. 2021. https://www.wrh.on.ca/aboutwrh. Accessed 29 May 2021. 
3. Fudge N, Sadler E, Fisher HR, Maher J, Wolfe CDA, McKevitt C. Optimising translational research opportunities: a systematic review and narrative synthesis of basic and clinician scientists' perspectives of factors which enable or hinder translational research. PLoS ONE. 2016;11(8):1-23.

4. Fort DG, Herr TM, Shaw PL, Gutzman KE, Starren JB. Mapping the evolving definitions of translational research. J Clin TransI Sci. 2017;1 (1):60-6.

5. Woolf SH. The meaning of translational research and why it matters. JAMA J Am Med Assoc. 2008;299(2):211-3.

6. Pickering $C R$, Bast RC, Keyomarsi K. How will we recruit, train, and retain physicians and scientists to conduct translational cancer research? Cancer. 2015;121:806-16.

7. Weston CM, Bass EB, Ford DE, Segal JB. Faculty involvement in translational research and interdisciplinary collaboration at a US academic medical center. J Investig Med. 2010;58(6):770-6.

8. Bakken S, Lantigua RA, Busacca LV, Bigger JT. Barriers, enablers, and incentives for research participation: a report from the ambulatory care research network (ACRN). J Am Board Fam Med. 2009;22(4):436-45.

9. Dao HD, Kota P, James JA, Stoner JA, Akins DR. Assessment of translational and interdisciplinary clinical research at an oklahoma health sciences center. J Okla State Med Assoc. 2015;108(3):93-101.

10. Campbell EG, Weissman JS, Moy E, Blumenthal D, Campbell EG, Weissman JS, et al. Status of clinical research in academic health centers: views from the research leadership. J Am Med Assoc. 2001;286(7):800-6.

11. Gehrke P, Binnie A, Chan SPT, Cook DJ, Burns KEA, Rewa OG, et al. Fostering community hospital research. CMAJ. 2019;191(35):E962-6.

12. Nonoyama ML, Mathur S, Herbert R, Jenkins H, Lobchuk M, McEvoy M. Past, present and future of respiratory research: a survey of Canadian health care professionals. Can Respir J. 2015;22(5):275-81.

13. Saurabh K, Ranjan S. Compliance and psychological impact of quarantine in children and adolescents due to Covid-19 pandemic. Indian J Pediatr. 2020;87:532-6.

14. Lynch EA, Ramanathan SA, Middleton S, Bernhardt J, Nilsson M, Cadilhac DA. A mixed-methods study to explore opinions of research translation held by researchers working in a Centre of Research Excellence in Australia. BMJ Open. 2018;8(9):e022357.

15. Cook DA, Wittich CM, Daniels WL, West CP, Harris AM, Beebe TJ. Incentive and reminder strategies to improve response rate for internet-based physician surveys: a randomized experiment. J Med Internet Res. 2016;18(9):e244.

16. Asch S, Connor SE, Hamilton EG, Fox SA. Problems in recruiting community-based physicians for health services research. J Gen Intern Med. 2000;15(8):591-9.

\section{Publisher's Note}

Springer Nature remains neutral with regard to jurisdictional claims in published maps and institutional affiliations.

Ready to submit your research? Choose BMC and benefit from:

- fast, convenient online submission

- thorough peer review by experienced researchers in your field

- rapid publication on acceptance

- support for research data, including large and complex data types

- gold Open Access which fosters wider collaboration and increased citations

- maximum visibility for your research: over $100 \mathrm{M}$ website views per year

At BMC, research is always in progress.

Learn more biomedcentral.com/submissions 